\title{
Analisis Implementasi Pembelajaran IPS Dalam Membentuk Karakter Nasionalisme Di MTs Miftahul Jannah Parakan Trenggalek
}

\author{
Guntur Guswantoro \\ STKIP PGRI Tulung Agung \\ GunturGuswantoro94@gmail.com \\ Sulastri Rini Rindrayani \\ STKIP PGRI Tulung Agung \\ rrindrayani@yahoo.com \\ Sunjoto \\ STKIP PGRI Tulung Agung \\ sunjoto@stkippgritulungagung.ac.id
}

\begin{abstract}
The implementation of the 2013 curriculum begins with designing the design of the learning planning program in the form of syllabus and learning implementation plans which are the elaboration of core competencies and basic competencies that have been set by the National Education Standards Agency. Conceptually the development of social studies education in Indonesia is inseparable from the development of universally developing Social Studies thinking. In social studies learning mainly discusses forming the character of nationalism where the definition of one's own character is quality or mental or normal strength, morals or individual character which is a special personality that becomes a driver and driver, and that distinguishes it from other individuals. On the contrary, the explanation of nationalism means stating the superiority of a group activity based on the similarity of language, culture and region.
\end{abstract}

Keywords: Implementation, Social Studies Learning, Character, Nationalism

\begin{abstract}
Abstrak
Implementasi kurikulum 2013, diawali dengan merancang desain program perencanaan pembelajaran berupa silabus dan rencana pelaksanaan pembelajaran yang merupakan penjabaran dari kompetensi inti dan kompetensi dasar yang sudah ditetapkan Badan
\end{abstract}


Standar Nasional Pendidikan. Secara konseptual perkembangan pendidikan IPS di Indonesia tidak bisa dipisahkan dari perkembangan pemikiran Social Studies yang berkembang secara universal. Dalam pembelajaran IPS terutama membahas membentuk karakter nasionalisme dimana definisi karakter sendiri itu adalah kualitas atau kekuatan mental atau normal, akhlak atau budi pekerti individu yang merupakan kepribadian khusus yang menjadi pendorong dan penggerak, serta yang membedakan dengan individu lain. Sebaliknya penjelesan nasionalisme berarti menyatakan keunggulan suatu aktivitas kelompok yang didasarkan atas kesamaan bahasa, budaya, dan wilayah.

\section{Kata Kunci: Implementasi, Pembelajaran IPS, Karakter, Nasionalisme}

\section{Pendahuluan}

Fenomena yang terjadi ini menunjukkan adanya gejala kemerosotan moral yang sangat mengkhawatirkan.Kebenaran, kejujuran, keadilan, tolong menolong dan kasih sayang sudah mulai menjadi barang mahal dan tertutup oleh penyelewengan, penipuan, penindasan, saling acuh tak acuh, mengambil hak orang lain, seks bebas dan masih banyak tindakantindakan menyimpang lainnya. Ironisnya tindakan-tindakan menyimpang ini banyak dilakukan oleh sebagian generasi muda bangsa ini, meskipun jumlahnya sepersekian dari jumlah pelajar secara keseluruhan, namun hal tersebut telah sedikit memberikan catatan yang kurang baik akan kredibilitas dunia pendidikan. Para peserta didik sebagai penerus peradaban seharusnya bisa menunjukkan karakter yang baik sebagai implementasi nilai dari salah satu tujuan pendidikan itu sendiri.Salah satu pendidikan yang dapat menerapkan pendidikan karakter adalah pendidikan sejarah.Karena dalam pendidikan sejarah terdapat tujuan yang secara tidak langsung dapat membentuk karakter peserta didik.Dunia pendidikan di Indonesia kini sedang memasuki masa-masa yang pelik.Kucuran anggaran pendidikan yang besar disertai berbagai program terobosan sepertinya belum mampu memecahkan persoalan mendasar dalam dunia pendidikan, yakni bagaimana mencetak alumni pendidikan yang unggul, yang beriman, bertaqwa, profesional, dan berkarakter. Oleh karena itu seperti negara berkembang lainnya, Indonesia kini sedang berusaha membangun karakter anak bangsa untuk memperbaiki citra bangsa sambil tetap mempertahankan identitas kulturalnya, proses ganda ini diusahakan dengan keseimbangan antara pertumbuhan dan pemerataan, sekaligus melestarikan pola kehidupan sosial budaya yang mendukung proses tersebut dalam rumusan yang lebih tepat dan sesuai.

Indonesia sedang berusaha bagaimana memantapkan kelangsungan psikologis dan kerangka proses perubahan yang lebih luas dalam membangun peradaban Pemerintah melalui Kementerian Pendidikan dan Kebudayaan sudah 
mencanangkan penerapan pendidikan karakter untuk semua tingkat pendidikan, dari SD sampai pada tingkat Perguruan Tinggi. Pembentukan karakter perlu dilakukan sejak usia dini. Munculnya gagasan program pendidikan karakter dalam dunia pendidikan di Indonesia, bisa dimaklumi, sebab selama ini dirasakan, proses pendidikan ternyata belum berhasil membangun manusia Indonesia yang berkarakter.

Pembentukan karakter khususnya generasi muda dibutuhkan peran sekolah.Sekolah sebagai lembaga formal yang membina generasi muda perlu direncanakan pelaksanaan pembelajaran IPS yang konseptual, sehingga bisa lebih efektif untuk membentuk karakter.Pandangan lain yang sejalan menegaskan bahwa pendldikan karakter adalah pendldikan budi pekerti, yaitu yang melibatkan aspek pengetahuan (cognitive), perasaan (feeling), dan tindakan (action) (Suyanto, 2010 dalam Anwas, 2010).Dalam jurnal ("Peran Pendidikan untuk Mengukuhkan Nasionalisme dan Membangun Karakter Bangsa Edy Suandi Hamid, 2016") Guru harus kreatif dalam menciptakan suasana kelas yang kondusif dan interaktif baik dalam proses pembelajaran di kelas maupun di luar kelas sehingga memberi pengalaman belajar yang bermakna untuk membentuk karakter peserta didik. Proses pembelajaran di luar kelas seperti pelaksanaan kegiatan ekstrakulikuler sebagai pengalaman peserta didik untuk menyeimbangkan antara teori dan praktek dalam menanamkan karakter kepada peserta didik dalam kehidupan bermasyarakat. Membina karakter peserta didik agar sesuai dengan harapan bukan berarti tanpa kendala.

Membina karakter peserta didik harus mencerminkan pencapaian secara komprehensif dari dimensi kognitif, afektif, dan psikomotorik.Pembelajaran IPS dalam pembentukan karakter perlu perjuangan yang berkesinambungan agar menghasilkan hasil yang sesuai dengan tujuan pendidikan nasional. Pelaksanaan pembelajaran IPS saat ini lebih cenderung kognitifintelektualistik, sehingga perlu diarahkan kembali.

Dari penelitian terdahulu pernah diteliti dengan judul yang berbeda yaitu peneliti Gita Enggarwati (2013) berjudul " Penanaman Sikap Nasionalisme Melalui Mata Pelajaran IPS Pada Siswa Kelas IV SD Negeri 2 Sumampir" Hasil Penelitian ini menyimpulkan bahwa cara guru untuk menanamkan sikap nasionalisme melalaui mata pelajaran IPS antara lain dengan pembiasaan, keteladanan, pemberian contoh yang kontekstual, pembelajaran melalui cerita dan media, seperti gambar pahlawan dan lagu nasional. Hal yang paling efektif dilakukan oleh guru diantara cara tersebut adalah pembiasaan dan keteladanan karena dapat dilakukan guru setiap hari. Perwujudan sikap nasionalisme siswa antara lain perilaku rela berkorban, cinta naha air, bangga sebagai bangsa Indonesia, persatuan dan kesatuan, patuh terhadap peraturan, disiplin, berani, jujur, serta bekerja keras. Perilaku siswa yang paling menonjol diantara aspek tersebut adalah kerja keras karena guru melakukan pembiasaan kepada siswa untuk aktif ketika pembelajaran. Penyebab terhambatnya penanaman sikap nasionalisme antara 
lain keterbatasan media pembelajaran, waktu, serta kesenjangan antara lingkungan keluarga dan masyarakat.

Wahana pengembangan pendidikan karakter bangsa, sebagai proses pembangunan kecerdasan, akhlak dan kepribadian peserta didik secara utuh sesuai dengan tujuan pendidikan nasional. Dalam mendisain kurikulum pendidikan IPS, termasuk dalam proses pembelajarannya, harus juga berangkat dari hakikat dan karakter peserta didik, bukan berorientasi pada materi semata. Proses pembelajaran IPS diarahkan untuk melahirkan pelaku-pelaku sosial yang berdimensi personal (misalnya, berbudi luhur, disiplin, kerja keras, mandiri), dimensi sosiokultural (misalnya, cinta tanah air, menghargai dan melestarikan karya budaya sendiri, mengembangkan semangat kebangsaan dan kesetiakawanan sosial, kepedulian terhadap lingkungan), dimensi spiritual (misalnya, iman dan taqwa, menyadari bahwa alam semesta adalah ciptaan Tuhan Yang Maha Pencipta), dan dimensi intelektual (misalnya, cendekia, terampil, semangat untuk maju) (Supardi, 2011: 190).

Berdasarkan uraian yang dipaparkan di atas, dapat disimpulkan bahwa pendidikan karakter adalah sebuah proses menumbuh kembangkan nilai-nilai kejujuran, ketaatan, kedisiplinan dan tanggungjawab terhadap organisasi sekolah serta mendewasakan kepribadian seseorang.

Peneliti disini menggunakan studi kasus merupakan pengujian secara rinci terhadap satu latar atau satu orang subjek atau satu tempat penyimpanan dokumen atau satu peristiwa tertentu.Membatasipendekatan studi kasus sebagai suatu pendekatan dengan memusatkan perhatian pada suatu kasus secara intensif dan rinci atau memberikan batasan yang lebih bersifat teknis dengan penekanan pada ciricirinya.Dimana di jelaskan bahwa dalam studi kasus hendaknya peneliti berusaha menguji unit atau individu secara mendalam.Para peneliti berusaha menernukan sernua variabel yang penting.

Berdasarkan batasan tersebut dapat dipahami bahwa batasan studi kasus meliputi: (1) sasaran penelitiannya dapat berupa manusia, peristiwa, latar, dan dokumen; (2) sasaran-sasaran tersebut ditelaah secara mendalam sebagai suatu totalitas sesuai dengan latar atau konteksnya masing-masing dengan maksud untuk mernahami berbagai kaitan yang ada di antara variabel-variabelnya.

Penelitian ini dilaksanakan di MTS MIFTAHUL JANNAH PARAKAN, yang terletak di Jalan Mastrip No. 150, Parakan,Trenggalek. Pemilihan lokasi penelitian ini didasarkan pada pertimbangan bahwa Mts Miftahul Jannah memiliki siswa yang cukup banyak dengan latar belakang sosial yang cukup beragam, maka tema yang diangkat dalam penelitian ini menjadi menarik untuk diungkapkan.

Teknik analisis data yang digunakan dalam penelitian ini adalah analisis data deskriptif kualitatif. Analisis data dalam penelitian dilakukan saat pengumpulan data dan setelah pengumpulan data. Analisis datamendeskripsikan tentang kendala yang dihadapi dalam pembiasaan nilai-nilai nasionalisme di MTS Miftahul Jannah.Data yang diperoleh berupa tulisan dan gambar yang merupakan jawaban dari pertanyaan penelitian. 


\section{Hasil dan Pembahasan}

\section{Pembelajaran IPS dalam membentuk karakter nasionalisme}

Karakter merupakan salah satu misi pembangunan nasional sebagaimana tercantum pada UU RI. No. 17 Tahun 2007 mengandung karakter yakni: "terwujudnya karakter bangsa yang tangguh, kompetitif, berakhlak mulia, dan bermoral berdasarkan Pancasila, yang dicirikan dengan watak dan perilaku manusia dan masyarakat Indonesia yang beragam, beriman dan bertakwa kepada Tuhan Yang Maha Esa, berbudi luhur, bertoleran, bergotongroyong, berjiwa patriotik, berkembang dinamis, dan berorientasi ipteks".Pentingnya karakter juga sesuai dengan tujuan pendidikan nasional yang tercantum pada UU. No 20 Tahun 2003 tentang Sisdiknas, pasal 3, yang dijelaskan bahwa pendidikan nasional berfungsi mengembangkan kemampuan dan membentuk watak serta peradaban bangsa yang bermartabat untuk mencerdaskan kehidupan bangsa, serta bertujuan untuk mengembangkan potensi peserta didik agar menjadi manusia yang beriman dan bertaqwa kepada Tuhan Yang Maha Esa, berakhlak mulia, sehat, berilmu, cakap, kreatif, mandiri, dan menjadi warga negara yang demokratis serta bertanggung jawab.

Pembelajaran IPS memiliki peran startegis untuk membina warganegara dalam membangun karakter bangsa.Karakter adalah seperangkat nilai yang telah menjadi kebiasaan hidup sehingga menjadi sifat tetap dalam diri seseorang.Pembentukan karakter khususnya generasi muda dibutuhkan peran sekolah.Sekolah sebagai lembaga formal yang membina generasi muda perlu direncanakan pelaksanaan pembelajaran IPS yang konseptual, sehingga bisa lebih efektif untuk membentuk karakter. Agar karakter peserta didik bisa dikembangkan sesuai dengan harapan bangsa dan negara, pembelajaran IPS perlu dikemas agar menarik dan mampu membina karakter peserta didik secara efektif dan efisien yang pada gilirannya nanti bisa diandalkan menjadi warganegara yang berkarakter sesuai dengan karakter Indonesia

\section{Kendala yang dihadapi guru IPS dalam membentuk karakter nasionalisme}

Pembentukan karakter nasionalisme antara siswa satu dengan siswa yang lainnya akan memiliki perbedaan. Ada yang mempunyai karakter yang berbeda dari yang lain, ada juga siswa yang masuk dalam kategori siswa yang memiliki karakter yang baik, kurang baik, bahkan masuk dalam kategori siswa yang memiliki karakter yang rendah. Hal ini bukan semata-mata karena guru yang tidak mampu dalam mendidik peserta didik, akan tetapi terdapat beberapa faktor internal yang menyebabkanlambatnya pembentukan karakter dari dalam diri siswa.

Kendala yang terjadi bisa terjadi bisa berasal dari kelancaran metode yang digunakan, teman sebaya, lingkungan sekitar, bahkan dirinya sendiri.Sama 
halnya dengan yang terjadi di MTS Miftahul Jannah. Seperti hasil wawancara peneliti dengan pak Suparlan,S.Pd sebagai berikut:

"Faktornya apa bayo kira-kira? Ya tentunya kemajuan teknologi sekarang, siswa lebih memilih untuk berinteraksi dengan gadget yang mereka punya dari pada dengan orang yang berada disekeliling mereka.Faktor ini sangat berpengaruh sekali untuk menghambat perkembangan kemampuan dan karakter sosial siswa.Dengan handphone, tablet, yang mereka mainkan itu menyebabkan siswa tidak memabami keadaan disekelilingnya. Dan menyebabkan mereka menjadi manusia yang individual"

Perencanaan pembelajaran Ilmu Pengetahuan Sosial (IPS) dalam pendidikan karakter di MTS Miftahul Jannah Parakan berupa Rencana Pelaksanaan Pembelajaran (RPP).Dari dokumentasi yang peneliti dapat Rencana Pelaksanaan Pembelajaran (RPP) guru IPS di MTS Miftahul Jannah Parakan menggunakan Kurikulum 2013. Didalam Rencana Pelaksanaan Pembelajaran (RPP) terdapat beberapa komponen yang harus ditetapkan secara matang dan terperinci antara lain sebagai berikut.

a. Merencanakan strategi pembelajaran dan menetapkan pendekatan metode dan teknik belajar mengajar yang dianggap paling tepat dan efektif sehingga dapat dijadikan peganganguru dalam melaksanakan kegiatan pembelajarannya.

b. Guru merencanakan media yang digunakan dalam kegiatan belajar berupa sarana yang dapat mempertinggi daya serap dan retensi anak terhadap materi pembelajaran.

c. Guru merencanakan Sumber belajar yang digunakan dalam pelaksanaan pembelajaran.

d. Guru merencanakan proses evaluasi.

Penelitian dengan wawancara, observasi, maupun dokumetasi yang telah peneliti lakukan mengenai pelaksanaan pembelajaran IPS dalam membentuk karakter nasionalisme. Peran guru IPS sebagai pendidik di MTS Miftahul Jannah Parakan selain menjalankan tugasnya dalam mengajar juga dapat di ketahui dari kegiatan lain, yaitu

Pada pelaksanaan pembelajaran yang berlangsung di kelas berbagai model pembelajaran yang dilakukan tiap-tiap guru IPS memiliki ciri khasnya masing-masing.Hal ini terlihat dari mulai kegiatan pendahuluan, kegiatan inti yang meliputi kegiatan eksplorasi, elaborasi, konfirmasi, dan kegiatan penutup.Perbedaan penggunaan model pembelajaran ini memberikan pengaruh yang berbeda pula pada pemahaman siswa terkait materi yang dijelaskan oleh tiap-tiap guru Seperti halnya di MTS Miftahul Jannah Parakan pelaksanaan pembelajaran yang berlangsung di kelas menggunakan beragam model pembelajaran yang berbeda-beda antara guru IPS satu dengan yang lainnya. 
Berdasarkan hasil wawancara dan dokumentasi sesuai dengan penyusunan perencanaan pembelajaran yang menjelaskan bawha semakin efektif strategi yang digunakan bapak / ibu guru IPS akan semakin terwujud secara maksimal pendidikan dalam membentuk karakter nasionalisme dalam pembelajaran IPS. Dari hasil observasi yang peneliti lakukan evaluasi pembelajaran yang diterapkan di MTS Miftahul Jannah Parakan banyak bentuknya karena setiap guru IPS memiliki berbagai Evaluasi yang berencana untuk mengetahui sejauh mana proses pelaksanaan program-program yang telah dilaksanakan untuk memberikan penilaian pada objek atau suatu keadaan mengunakan instrument yang hasilnya kemudian dibandingkan dengan komponen-komponanya yang terukur.

Karakter tersusun dari tiga bagian yang saling berhubungan yaikni: moral knowing (pengetahuan moral), moral feeling (perasaan moral), dan moral behaviiour (perilaku moral). Karakter yang baik terdiri dari pengetahuan tentang kebaiikan (knowing the good), keinginan terhadap kebaikan (desiring the good), dan berbuat kebaikan (doing the good).Dalam hal ini, diperlukan pembiasaan dalam pemikiran (babits of the mind), pembiasaan dalam hati (babits of the heart) dan pembiasaan dalam tindakan (babits of the action). Ketika kita berpikir tentang jenis karakter yang ingin ditanamkan pada diri remaja-remaja, hal ini jelas kita menginginkan agar remaja-remaja mampu menilai apakah hak-hak asasi, peduli secara mendalam apakah hak-hak asasi, dan kemudian bertindak apa yang diyakini menjadi hak-hak asasi. Karakter pada dasarnya diperoleh lewat interaksi dengan orangtua, guru, teman, dan lingkungan. Karakter diperoleh dari hasil pembelajaran secara langsung atau pengamatan terhadap orang lain.

\section{Kesimpulan}

Berdasarkan hasil penelitian dan pembahasan internalisasi nilai-nilai nasionalisme dalam pembelajaran IPS diMTS Miftahul Jannah Parakan Trenggalek, dapat di simpulkan bahwa pelaksanaan pendidikan karakter di MTS Miftahul Jannah Parakan dilakukan melalui tiga tahap yaitu: a. Pada tahap perencanaan, dengan melakukan beberapa program perencanaan, diantaranya: 1) Jenis karakter yang akan ditanamkan kepada siswa kelas VII, VIII, dan IX dengan mengutamakan karakter religious, disiplin, jujur dan cinta tanah air, 2) Sistem pelaksanaan pendidikan karakter religious, disiplin, jujur dan cinta tanah air ,3) Sistem evaluasi pendidikan karakter religious, disiplin, jujur dan cinta tanah air. Pada tahap pelaksanaan, dilakukan dengan beberapa program, mengoptimalkan pembelajaran IPS agar proses pembentukan karakter nasionalisme dapat berlangsung dengan baik. Mengoptimalkan proses pembentukan karakter nasionalisme sehingga peserta didik mempunyai rasa cinta terhadap bangsa Indonesia.

\section{Daftar Pustaka}


Asih 2014 Implementasi Kurikulum2013 Pada Mata Pelajaran IPS Di Sekolah Menengah Pertama (Smp) Negeri 1 Blado

Machin 2014 Implementasi Pendekatan Saintifik, Penanaman KarakteDan Konservasi Pada Pembelajaran Materi Pertumbuhan

Amelia etal, 2014 Penanaman Sikap Nasionalisme Siswa Kelas XI IPS SMA Negeri 1 Pecangaan

Amri Marzali,2013Struktural-Fungsionalisme

Dina Anika Marhayani Stkip Singkawang 2017pembentukan Karakter Melalui Pembelajaran IPS Fkip-utm 2013Pendidikan karakter dalam kurikulum 2013

Idha Winarsih, dkk 2013 Peranan Pembelajaran Sejarah dalam Penanaman Nilai Karakter Religius dan Nasionalisme di MAN Temanggung Tahun Ajaran 2016/2017

Murni Eva Marlina, 2013 KURIKULUM 2013 YANG BERKARAKTER

Muhammad Ali Ramdhani, 2013 Lingkungan Pendidikan dalam Implementasi Pendidikan Karakter

Nyoman Sadra DharmawanUniversitas Udayana, Denpasar 2014 Implementasi PendidikanKarakter Bangsa Pada Mahasiswa DiPerguruan Tinggi

Pgsd, Alma, and Yogyakarta 2017 Implementasi Pendidikan Nilai Nasionalisme dalam Pembelajaran Living Values

Rizka Amalia. A, dkkUniversitas Muhammadiyah Sidoarjo2016 Teori Behavioristik Purnomo Sidi, 2014 Krisis KarakterDalam Perspektif Teori Struktural Fungsional

Sadono dkk, 2014 Keefektifan Vct Dalam Pembelajaran Sejarah Untuk Meningkatkean Nilai Nasionalisme, Demokrasi, Dan Multikultural Wahid and Yogyakarta, 2016 Implementasi Pendidikan Karakter dalam Pembelajaran IPS di Madrasah Aliyah Widiatmaka Pipit, 2016 Pembangunan Karakter Nasionalisme Peserta Didik Di Sekolah Berbasis Agama Islam 